\title{
Accuracy of Working Length Measured by Apex Locator and Digital Radiography
}

\author{
Ghulam Ishaq Khan ${ }^{1}$ \\ BDS \\ Muhammad Talha Khan² \\ BDS, FCPS \\ BDS, FCPS \\ BDS, FCPS \\ BDS, FCPS \\ BDS, FCPS
}

OBJECTIVE: The objective of this study was to compare the measurements of electronic and radiographic method of working lengths calculation with actual working length of root canals. Precise working length determination is the most important part for successful root canal procedure. The most commonly used methods to determine the working length in root canal treatment are radiography and electronic apex locator.

METHODOLOGY: A cross sectional study was done over a period of 06 months in the Department of Operative Dentistry, Fatima Memorial Hospital, Lahore. Sixty patients who were recommended extraction of their premolar teeth with sixty canals were selected by convenience sampling. The Root $\mathrm{ZX}^{*}$ apex locator was used to determine electronic working length exactly identifying the apical constriction. Reference points were identified and radiographic working length were determined $1 \mathrm{~mm}$ short of radiographic apex. The teeth were extracted along with file cemented before extraction inside root canal. The actual length of the root canal was then calculated using the same files and reference point with $3.5 \mathrm{X}$ magnification. Pearson chisquare test was applied to compare the apex locator and digital radiographic measurement with actual working length. RESULTS: The Root ZX® apex locator was $95 \%$ accurate to identify the apical constriction as compared $70 \%$ accuracy given by radiographs within $0.5 \mathrm{~mm}$ of the apex.

CONCLUSION: Electronic apex locator was more accurate as compared to digital radiography in working length determination. KEYWORDS: Working length (WL), Electronic apex locators (EAL), Radiographic working length(RWL), Apical constriction (AC)

HOW TO CITE: Khan GI, Khan MT, Ehsan S, Fayyaz A, Malik HA, Hussain S. Accuracy of working length measured by apex locator and digital radiography. J Pak Dent Assoc 2021;30(1):24-28.

DOI: https://doi.org/10.25301/JPDA.301.24

Received: 19 October 2020, Accepted: 11 December 2020

\section{INTRODUCTION}

$\mathrm{R}$ oot canal treatment (RCT) is the most commonly used method to treat pulpal and periapical infections. Root canal treatment is a multiple visit procedure which includes access cavity preparation, creating the patency

1. Demonstrator, Department of Operative Dentistry, Bacha Khan Dental College, Mardan.

2. Senior Demonstrator, Department of Operative Dentistry, Fatima Memorial Hospital, Lahore.

3. Associate Professor, Department of Operative Dentistry, Fatima Memorial Hospital, Lahore.

4. Assistant Professor, Department of Operative Dentistry, Lahore Medical and Dental College, Lahore.

5. Senior Demonstrator, Department of Prosthodontics, Fatima Memorial Hospital, Lahore.

6. Assistant Professor, Department of Prosthodontics, Rehman College of Dentistry, Peshawar.

Corresponding author: “Dr. Muhammad Talha Khan” < dr_talhakhan@ @otmail.com> of root canals, working length determination, pulp removal, biomechanical canal preparation, obturation and restoration of broken coronal tooth. ${ }^{1}$ Working length (WL) determination is the crucial step for root canal treatment and is described as the distance from coronal fixed point to the apical constriction of root canal space. ${ }^{2,3}$ Moreover, apical constriction (AC) is an important land mark at apical part of root canal space of tooth. Working length can be calculated by paper points, tactile sensation, conventional radiographs, digital radiographs and electronic apex locator. Working length calculation is important part of root canal procedure. Digital radiography employs intraoral sensor in place of conventional radiographic film with added advantages of less radiation dose, good image quality, no processing time along with magnifying and storing digital image. ${ }^{3}$ On the 
other hand, locating apical constriction clinically and radio graphically is tough due to its variable shape and position. ${ }^{2}$ Mostly apical constriction is located 0.5 to $2.0 \mathrm{~mm}$ from apical foramen. ${ }^{3,4}$ The cleaning, shaping and obturation of the root canal system cannot be achieved precisely without determining accurate working length of tooth. ${ }^{5-8}$

However, there are many limitations in using digital radiography for working length calculation. The precision is mainly affected by magnification of image, radiographic analysis errors, location of apical foramen, curvature of root and two dimensional picture that is often masked by surrounding anatomic structures. ${ }^{9}$

The use of electric current to determine working length was first reported by Custer. ${ }^{8}$ According to Suzuki et al the electrical resistance between the oral mucosa and periodontal ligament was, a constant value of, 6.5 kilo ohms and this can be used to determine the accurate position of apical constriction where the canal ends at the periodontal ligament. ${ }^{10}$

In modern endodontic practice electronic apex locator is a useful device for exact position of apical constriction. Kim at al found it to be $84 \%$ accurate in determining the location of apical constriction. Acosta et al compared four different apex locators and found $81 \%$ to $89 \%$ success rate in locating apical constriction. However, there are many limitations of apex locator with regard to metallic restorations, in patients having heart pace maker, display varying and unstable reading and is expansive. ${ }^{11}$

Cianconi L.et al study compared the accuracy of three different types of electronic apex locators and digital radiography working lengths and the result was $84 \%$ accuracy with apex locator and with digital radiography $51 \%$ accuracy within $\pm 0.5 \mathrm{~mm}$ of apical foramen. ${ }^{9}$

In spite of modern technology and good technique, there is still dispute of the ideal technique for measurement of WL during RCT. The apical constriction of root canal cannot be precisely determined clinically due to anatomical variations. According to some studies radiographs are more accurate while others support the apex locator. There is also enough literature showing that there is no statistical difference between the two methods. ${ }^{10-12}$

Mostly previous studies ${ }^{3-6}$ are done with conventional radiography only and most studies are in vitro. Therefore, the aim of study was to conduct a comparative in vivo study to determine the accuracy in working lengths by apex locator and digital radiography and to compare their accuracy with the actual working length after extraction so that a better modality can be selected for good clinical outcome.

\section{METHODOLOGY}

This study was approved from ethical review board of institution via letter no FMH-03-2020-IRB-751-M before the start of study. This cross sectional study was done on 60 patients of both sexes aged 20-60 years requiring extraction of their maxillary and mandibular premolar teeth for periodontal, prosthetic and/or orthodontic purposes. All teeth had fully formed apices of root. Teeth with root resorption, metallic restorations and previously RCT treated were not included in the study. The patients were selected by convenience sampling from the Operative Dentistry department of Fatima Memorial Hospital, Lahore. Sample size of 60 cases was calculated with $95 \%$ confidence, $13 \%$ margin of error and taking expected percentage of accuracy of working length measured by digital radiography i.e. 51\% in teeth intended for extraction. Before starting study Informed consent was taken from all the patients. A detailed medical and dental history was documented.

After giving local anaesthesia, endodontic access cavity was prepared using high speed hand piece with a number (04) and (02) round tungsten carbide bur. Coronal reference point was fixed and all pulp tissue was removed using spoon shaped excavator and barbed broaches \#15 and then \#20. After irrigation of the root canal, paper point was used to dry the canal. Apex locator WL (ALWL) was calculated by digital reading with manual K File No. 20 from coronal fixed point to apical constriction by using Dentaport Apex Locator (J. Morita Co, Tustin, CA). Radiographic WL (RWL) was calculated before extracting the tooth by inserting the No $20 \mathrm{~K}$-file with fixed coronal reference point to $1 \mathrm{~mm}$ short of radiographic working length by parallel technique using periapical X-ray (Kodak Digital System). Access opening was packed with GIC, Ketac Molar Easy Mix (3M ESPE) with the files present in canals, without removing handles of files. The resident of maxillofacial surgery department was requested to extract the tooth atraumatic ally, which was later disinfected, dried and labelled.

Actual working length (AWL) was calculated by longitudinal sectioning of apical $1 / 3$ of root with a diamond tapered fissure diamond bur till the file present in the canal became visible. The distance of the file tip from fixed coronal point to anatomic apical constriction was calculated in millimetres with the help of scale and endodontic loupes (CE Dental Surgical Binocular Loupes 3.5X320mm). Actual working length was taken as gold standard to determine the accuracy of electronic apex locator and digital working length measurements.

Criteria for accuracy of determined working length i.e. the Accurate working length (AWL) for ALWL and RWL respectively:

\begin{tabular}{|l|l|l|l|}
\hline S. No & Apex Locator WL(ALWL) & Radiographic WL (RWL) & Accuracy \\
\hline 1. & File at apical constriction & File within $0.5 \mathrm{~mm}$ of apical constriction & Yes \\
\hline 2. & $\begin{array}{l}\text { File short or beyond apical } \\
\text { constriction }\end{array}$ & $\begin{array}{l}\text { File short or beyond } 0.5 \mathrm{~mm} \text { of apical } \\
\text { constriction }\end{array}$ & No \\
\hline
\end{tabular}


Data analysis was completed by using SPSS version 20 for the analysis. Descriptive statistics of mean and standard deviation were computed for quantitative variables e.g. working length in millimetre and age. Frequency and percentages were calculated for gender.

Accurate working length (AWL) was calculated for radiography readings within $0.5 \mathrm{~mm}$ of actual working length and for apex locator readings, exactly at apical constriction. Data was stratified for age and gender to address the effect modifier. Chi-square test was used post-stratification to check the level of significance.

The age group were divided into four group $(\mathrm{g} 1=20-30$, $\mathrm{g} 2=31-40, \mathrm{~g} 3=41-50, \mathrm{~g} 4=51-60)$ for the accuracy of working length for both ALWL and RWL and to know effect of this variable on the working length determination.

\section{RESULTS}

Total 60 single rooted teeth both maxillary and mandibular premolars from 60 patients were included in the study. There were $35(58.33 \%)$ male participants and $25(41.67 \%)$ female participants in the study.

The mean age of the patients in this study was $37.8 \pm$ 8.55. The mean ALWL was 20.88 \pm 1.61 , RWL was $21.45 \pm 1.73$ and AWL was 20.87 \pm 1.57 .

Table 1 shows ALWL and RWL falling into the accurate category.

Table1 : Accuracy of working length by radiograph and apex locator

\begin{tabular}{|l|l|l|l|}
\hline S. No & Accurate Reading & ALWL & RWL \\
\hline 1 & Yes & $57(95 \%)$ & $42(70 \%)$ \\
\hline 2 & No & $3(5 \%)$ & $18(30 \%)$ \\
\hline
\end{tabular}

The results were also formulated for gender wise accuracy of both radiography and apex locator readings. Table 2 demonstrates the data. The results demonstrated no statistically significant association between age and ALWL, $\mathrm{p}=0.368$, and RWL, $\mathrm{p}=0.775$, respectively, when they were compared with AWL.

Table 2: Gender wise accuracy of both radiography and apex locator readings

\begin{tabular}{|l|l|l|l|}
\hline S. No & Accurate Readings & ALWL with AWL & RWL with AWL \\
\hline 1 & Male & $58(96.6 \%)$ & $41(68.3 \%)$ \\
\hline 2 & Female & $55(91.6 \%)$ & $43(71.6 \%)$ \\
\hline
\end{tabular}

The results were also formulated for age groups, G1=20$30, \mathrm{G} 2=31-40, \mathrm{G} 3=41-50, \mathrm{G} 4=51-60$, and accuracy of both ALWL and RWL respectively. The result $\mathrm{p}=0.446$ related that there was no statistically significant association between age groups when RWL was compared with AWL. While for age and ALWL compared to AWL, $\mathrm{p}=0.021$ showed statistically significant association. The result showed that the age of the patient had an effect on accuracy of apex locator.

\section{DISCUSSION}

Determining AWL is a crucial step in root canal treatment. The success of root canal treatment depends on accurately determining the working length. According to most dentists the apical constriction is apical end of root canal space. All the root canal preparation and obturation should be restricted to apical constriction for good long-term prognosis of treatment. Precisely locating the apical constriction is difficult because of its variable shape and position. According to most of the studies apical constriction is $0-3 \mathrm{~mm}$ with in radiographic apex. ${ }^{19}$

The results of this study confirmed the results of previous studies which revealed that electronic apex locator can accurately determine the apical constriction in $90 \%$ of canals. ${ }^{13-19}$ These results agree with the study of Schweiz ${ }^{20}$ who also compared radiographic and electronic working lengths and results showed $77.2 \%$ of the measured radiographic lengths within $0.5 \mathrm{~mm}$ of the apical constriction. The results of electronic apex locator were $<0.5 \mathrm{~mm}$ of the apical constriction $98.5 \%$ of the time. However, the results of accuracy of apex locators were more reliable $(95 \%$ in this study) than the radiographic accuracy ( $70 \%$ in this study).

These results are alike with the results of El Ayouti who established that the radiographic working length measurements were extended in $56 \%$ of the premolars under examination. ${ }^{21}$ The results of that study showed that the use of Root ZX apex locator decreased the overestimation of working length of the premolars to $21 \%$. This may be due to location of apical constriction laterally in $78 \%$ to $93 \%$ of the cases. The result of another study by Pineda F. et al also showed that electronic working length by apex locator were more precise in determining the apical constriction than the digital radiograph. ${ }^{22}$

The results of this study showed that if a file is placed at the radiographic apex, its tip will, in most cases, cross the apical foramen and if root canal filling is done, it will be over obturated in almost all the cases. If the file was set $1 \mathrm{~mm}$ short of the radiographic apex the accuracy was $70 \%$ within $0.5 \mathrm{~mm}$ of actual working length and almost $98 \%$ within $1.0 \mathrm{~mm}$ actual working length. Therefore, the obturation of root canal within $2 \mathrm{~mm}$ of radiographic apex are said to be satisfactory from clinical point of view. With the increasing age, certain physiological changes occur in root apex due to cellular cementum deposition. The successive deposition of cementum is responsible for change in root 
morphology in term of diameter, size and position of apical foramina and may affect the accuracy of radiography and apex locator with respect to root apex. ${ }^{24-27}$ The RWL showed an average $70 \%$ accuracy in different age groups, meaning that there is change in position of apical constriction (AC) when the measurements were taken from root apex. These findings were inconsistent with the studies of Kuttler showing that up to $80 \%$ teeth having deviated from major apical foramina. Another study by Levy and Glatt stated that $66.4 \%$ deviation percentage of apical foramina. ${ }^{25}$

Apex locator in age groups shows $88.3 \%$ accuracy with p-value of 0.021 which was statistically significant. The reason can be due to electronic apex locator ability to precisely measure the apical constriction and working length measured by electric signal. The accuracy of radiograph mostly relies on assessment of working length with respect to root apex and position of apical foramina may vary its position with chronological age.

Therefore, the result of the study shows greater accuracy of apex locator readings when compared to accuracy of radiographic readings.

The limitations of this study were that sample size was small and after extraction instead of microscope only endodontic loups and scale were used to measure the distance of the file tip from fixed coronal point to anatomic apical constriction

\section{CONCLUSION}

From clinical standpoint, the Root ZX apex locator showed 95\% accuracy to determine actual working length. Radiographs showed $70 \%$ accuracy within $\pm 0.5 \mathrm{~mm}$ of actual working length and $98 \%$ accuracy within $1.0 \mathrm{~mm}$ of actual working length.

Within the limitations of the study it is suggested that apex locator can be a better treatment strategy for determining working length for RCT procedures. The combined use of electronic apex locator and radiographs can enhance the accuracy of working length determination and length control throughout the root canal treatment.

\section{CONFLICT OF INTEREST}

None to declare

\section{REFERENCES}

1. Siqueria JF. Etiology of root canal treatment failure: why well treated teeth can fail. Int Endod J 2001;34:1-10.

https://doi.org/10.1046/j.1365-2591.2001.00396.x
2. Ehsan S. Comparative role of radiograph and electronic apex locator in working length determination. Pak Oral Dental J 2011; 31:187-90

3. Iqbal Z, Memnon RA. Comparison between radiographic and electronic working length determination in root canal treatment in vivo study. Isra Med J 2013; 5:41

4. Sheikh H, Alothmani OS, Friedlander LT, Chandler NP. Radiographic assessment of endodontic working length. Saudi Endod J 2013; 3:5764

https://doi.org/10.4103/1658-5984.118145

5. Inoue N, Skinner DH. A simple and accurate way of measuring root canal length. JOE 1985; 11:421.

https://doi.org/10.1016/S0099-2399(85)80079-0

6. Bramante CM, Berbert A. A critical evaluation of methods of determining tooth length. Oral Surg Oral Med Oral Path 1974;37:463. https://doi.org/10.1016/0030-4220(74)90122-4

7. Seidberg BH, Alibrandi BU, Fine H, Logue B. Clinical investigation of measuring working length of root canals with an electronic device and with digital tactile sense. J Am Dent Assoc 1975;90:379.

https://doi.org/10.14219/jada.archive.1975.0059

8. Custer LE. Exact methods of locating the apical foramen. J Natl Dent Assoc 1918;5:815.

https://doi.org/10.14219/jada.archive.1918.0368

9. Cianconi L, Angotti V. Accuracy of three electronic apex locator compared with digital radiography: An ex vivo study. J Endod 2010;36:2003-07

https://doi.org/10.1016/j.joen.2010.08.036

10. Suzuki K. Experimental study on ionophoresis. J Jpn Stomatol 1942;16:411.

https://doi.org/10.5357/koubyou1927.16.6_411

11. Fabiano K, Pereira S. An in vi o study of working length determination with new apex locator. Braz Dent 2014:25:17-21 https://doi.org/10.1590/0103-6440201302326

12. Ghazal T, Ahmed MA, Naz F, Amin M. Comparison of accuracy of working length measured by apex locator and periapical radiograph. Pak Oral Dent J. 2015; 35:531-4

13. Qiam F, Rehman K, Mehboob B, Kamran M. An in vivo study to evaluate the efficacy of electronic apex locators in the determination of working length. J Khyber Coll Dent. 2011;1:62-5

14. Sadaf D, Ahmad MZ. Accurate measurement of canal length during root canal treatment: an in vivo study. Int J Biomed Sci. 2015;11:4247.

15. Ounsi HF, Namaan A. In vitro evaluation of the reliability of the root zx electronic apex locator. 1999:32:120-23

https://doi.org/10.1046/j.1365-2591.1999.00202.x

16. Mcginty DT, Fabre DD, Miller DA, Lautenschlager EP. Do irrigants 
Khan GI/ Khan MT/ Ehsan S/ Fayyaz A/ Malik HA/ Hussain S

affect the precision of apex locators? J endodon 1996; 22:195. https://doi.org/10.1016/S0099-2399(96)80127-0

17. Jenkins JA, Walker War, Schidler WG, flores $\mathrm{cm}$. An in vitro evaluation of the accuracy of root $\mathrm{zx}$ in the presence of various irrigants. J Endodon 2002; 27:209-11.

https://doi.org/10.1097/00004770-200103000-00018

18. Dunlap CA, Remeikis NA, Begole EA, Rauschenberger CR. An in vivo evaluation of an electronic apex locator that uses the ratio method invital and necrotic canals. J endodon 1998; 24:48-50. https://doi.org/10.1016/S0099-2399(98)80214-8

19. Welk AR, Baumgartner JC, Marshall JG. An in vivo comparison of two frequency based electronic apex locators. J endodon 2003; 29:497-500.

https://doi.org/10.1097/00004770-200308000-00002

20. Mente J, Seidel J, Buchalla W, Koch MJ. Electronic determination of root canal length in primary teeth with and without root resorption. J Endodon 2002; 35:447-52.

https://doi.org/10.1046/j.1365-2591.2002.00500.x

21. Kielbassa AM, Muller U, Munz I, Monting JS. Clinical evaluation of the measuring accuracy of root zx in primary teeth. Oral Surg Oral Med Oral Path 2003; 95:94-100.

https://doi.org/10.1067/moe.2003.99
Accuracy of working length measured by apex locator and digital radiography

22. Schweiz MZ. In vitro comparison of electronic root canal length measuring device and the radiographic determination of working length. 2001;111:1165-70.

23. Elayouti A, Weiger R, Lost C. The ability of root zx apex locator to reduce the frequency of overestimated radiographic working length. J Endodon 2002; 28:116-19.

https://doi.org/10.1097/00004770-200202000-00017

24. Pineda F, Kuttler Y. Mesiodistal and buccolingual roentgenographic investigation of 7,275 root canals. Oral surg oral med oral path 1972; 33:101-10.

https://doi.org/10.1016/0030-4220(72)90214-9

25. Shabahang S, Goon WW, Gluskin AH. An in vivo evaluation of root zx electronic apex locator. J Endodn 1996; 22:616-18. https://doi.org/10.1016/S0099-2399(96)80033-1

26. Morfis A,Sylarus S, Prountzos F. Study of apices of human permanent teeth with the use of scanning electron microscope. Oral Surg Oral Med Oral Pathol 1994; 77:172-6

https://doi.org/10.1016/0030-4220(94)90281-X

27. Burch JG, Hulen S.The relationship of the apical foramina to the anatomic apex of tooth. Oral Surg Oral Med Oral Pathol 1972; 24:2628

https://doi.org/10.1016/0030-4220(72)90418-5 